\title{
The Career Experiences of Female Registered Dietitians in NCAA Division I Athletic Departments
}

\author{
Lauren Antle, Lauren Beasley, and Robin Hardin \\ The University of Tennessee
}

\begin{abstract}
NCAA member institutions began to have the option to provide unlimited meals and snacks to athletes in 2014, and this change in policy created a need for fulltime registered dietitians (RDs). This position was necessary to ensure athletes were receiving proper nutritional guidance. This has created a professional niche for RDs as they are now considered to be a key member of the college athlete holistic care team. However, there is a lack of research exploring the experiences and challenges of this emerging profession in college athletic departments. Thus, the purpose of this study was to examine the career experiences of RDs working in NCAA Division I athletic departments. Nine RDs participated in semi-structured interviews, and three themes were constructed from the data analysis: (a) professional transition; (b) nutritional education; and (c) (dis)respect. The respondents discussed their participation in sport or volunteer experience was what pushed them to pursue a career as a sports dietitian. One of the primary functions of their position is to build trust with the athletes and provide them with nutritional education so they will develop healthy eating habits. The respondents also struggled with a lack of acceptance of the importance of their position on the interprofessional care team. Some have positive experiences with administrators, but most have negative experiences and a general lack of understanding of the professional expertise they had.
\end{abstract}

Keywords: Holistic care, Student-athletes, Nutrition, Career mobility, Women

The National Collegiate Athletic Association (NCAA) passed legislation in 2014 to allow unlimited meals and snacks to athletes at member institutions with the intent to meet their nutritional needs (2020-21 Division I Manual, 2020; Hosick, 2014). Prior to this legislation, NCAA members were only allowed to offer one training table meal a day and snacks that were limited to fruits, nuts, and bagels (Hosick, 2014; NCAA Academic and Membership Affairs Staff, 2013). This policy change created a need for full-time registered dietitians (RDs) to ensure athletes are properly fueled and monitor their dietary habits. This also resulted in an increase in the number of registered dietitians working in collegiate athletic departments. There was 
a $70 \%$ increase in the number of universities who employed at least one full-time dietitian from 2013 to 2017 (Collegiate and Professional Sports Dietitians Association, n.d.). RDs are now considered to be a key member of the college athletes holistic care team (McHenry et al., 2020; Waller et al., 2016). This has created a unique professional niche for RDs, but there is a lack of research exploring the experiences of this emerging profession in college athletic departments. Thus, the purpose of this research is to examine the career experiences of RDs working in NCAA Division I athletic departments.

This change in policy for unlimited meals was prompted by one visible incident and one proposal made in 2012. The visible incident involved Connecticut basketball player Shabazz Napier. Napier was being interviewed during the NCAA men's basketball tournament and noted that were many nights that he went to bed hungry (Phillips, 2014). This brought a great deal of attention to the idea of unlimited meals for college athletes. This change had actually been brought to the NCAA by the Collegiate and Professional Sport Dietitians Association (CPSDA) in 2012 in a report that indicated college athletes were not receiving proper nutrition. The report also advocated for the for the inclusion of RDs in collegiate athletic departments (Collegiate and Professional Sport Dietitians Association, 2012). It took two years for the proposal to work itself through the bureaucracy of the NCAA and to the Division I Legislative Council (Jessop, 2014). It was a perfect scenario to have the momentum to pass the unlimited meals provisions with the support of the CPSDA. The other key aspect of this change is that member institutions could choose to provide unlimited meals if financial resources allowed it. Member institutions could also choose to provide some other variance of one meal a day to unlimited meals (2020-21 Division I Manual, 2020).

\section{Holistic Care}

Holistic care grew out of the concept of holism, the idea that the whole is better than its parts (Smuts, 1926). Applied in the healthcare setting, holism situates health as physical, mental, and spiritual well-being, and true care means attention to each aspect of the person (Waller et al., 2016; Zamanzadeh et al., 2015). Therefore, a physical injury cannot be fully healed without also healing the mental and spiritual impacts of the injury. In response, a reimagined concept to healthcare - in contrast to the traditional medical model-emerged. Termed holistic, collaborative, interdisciplinary, or interprofessional care, healthcare is provided to individuals by a variety of professions, including medical doctors, behavioral health specialists, psychiatrists, chaplains, social workers, dietitians, and other helping professionals (Burns et al., 2004; McHenry et al., 2020; Raney, 2015; Waller et al., 2016). Models of holistic care have become a best practice in all aspects of healthcare due to its focus on the whole person (Leung et al., 2018; Tjale \& Bruce, 2007).

The holistic care model has also recently become popularized in collegiate athlete wellness (Barkley et al., 2018; McHenry et al., 2020; Waller et al., 2016). Similar to holistic care programming in healthcare, there are many stakeholders in the holistic care model for college athletes ranging from coaches, to athletic trainers, to 
chaplains, to dietitians. Understanding each professional's role is imperative to the well-being of athletes (Berg \& Warner, 2019). However, due to the infancy of the model (Waller et al., 2016), there is some, albeit limited, research on the different types of professionals that provide care to athletes. Arvinen-Barrow and Clement (2015) did explore the role of athletic trainers in the care of athletes, and found that they were identified as the point person in the holistic care team due to their close relationship to the athletes (i.e., seeing them daily). Beasley and colleagues (2019) also qualitatively explored the work experiences of social workers working in collegiate athletic departments. The findings suggested that social workers were an important part of the holistic care team, but misunderstanding of their role by other members of the holistic care team hindered effective interprofessional care. Research on sport chaplains has focused on college athletic directors' perception of the value of the role (Hardin et al., 2019) as well as their role in the holistic care model of college athletes (Huffman et al., 2016). The role of certified mental performance coaches has been examined as well in regards to their value, desired characteristics, and contributions to athletic success (Schimmel et al., 2014; Wrisberg et al., 2012; Zakrajsek et al., 2016). Academic advisors have been examined as well in their role in providing support for college athletes and their overall success both in and out of competition (Hardin et al., 2020; Hardin \& Pate, 2013; Pate et al., 2011). There seems to be consensus that support staff personal are critical in supporting collegiate athletes but those positions do not always take priority in the overall staff of collegiate athletic departments. Athletic directors have indicated that the education and personal development of collegiate athletes is important but are not always made a priority in terms of staffing and funding (Wood et al., 2018). Regardless, it is important to understand the experiences of these the members of the holistic care team for collegiate athletes and that includes registered dietitians.

\section{The Role of Registered Dietitians in Interprofessional Teams}

Interprofessional teams have been defined as "an integrative cooperation of different health professionals, blending complementary competence and skills, to the benefit of the patient, making possible the best use of resources" (Samuelson et al., 2012 , p. 205). RDs, with their nutritional competencies and expertise, are an essential member of interprofessional teams across healthcare settings (Casas-Agustench et al., 2020; Eliot \& Kolasa, 2015; Jortberg \& Fleming, 2014; Mailliet et al., 2013). Specifically, research has found that including RDs in patient care plans lead to better health outcomes due to the changes in dietary habits (Casa-Agustench et al., 2020; Warner et al., 2018). RDs are also essential in preventative healthcare practices (Jortberg \& Fleming, 2014) and in eating disorder care teams (Thomas, 2000). The role of RDs in interprofessional teams is to provide nutritional counseling, patient self-management support, and care management services (Jortberg \& Fleming, 2014).

Interprofessional teams are the collaboration of many different professionals in the care of athletes and is considered a best practice (Newman et al., 2019; Samuelson et al., 2012; Waller et al., 2016). The RD is just one member of the interprofes- 
sional care team, and provides nutritional guidance and counseling. These teams can also include mental health counselors and social workers to care for the emotional needs of athletes. Certified Mental Performance Coaches (CMPC) are available to assist with issues related to athletic performance, and chaplains are a part of this team to tend to the spiritual needs of athletes. Strength and conditioning coaches ensure the physical development and physical maintenance of athletes. Athletic trainers are key member of this team to aid in injury rehabilitation as well as injury prevention. Academic counselors are vital component in the college athletic setting to provide guidance in major selection, class selection, tutoring, and maintaining academic eligibility. It takes all of these team members working together to ensure college athletes have the opportunity to perform at their best both athletically and academically as well as develop into young professionals in their chosen career path (Waller et al., 2016).

However, there are challenges to the inclusion of RDs in these teams. Other healthcare professions may not see the value of an RD due to lack of knowledge on the dietetic professions (Siopis et al., 2020) and unclear roles delineations (Gurau et al., 2013). Dejesse and Zelman (2013) found many challenges associated with interprofessional care teams comprised of RDs and mental health providers working with eating disorder patients. The main issues identified were lack of communication, role encroachment, placing the patient as the middle person for communication between the two professionals, lack of specialized knowledge on eating disorders, and conflicting treatment strategies.

Addressing these challenges of including RDs on interprofessional care teams is important as Eliot and Kolasa (2015) suggest that including RDs in an interdisciplinary approach is essential when issues include "eating disorders, human immunodeficiency virus/acquired immune deficiency syndrome, coronary heart disease, diabetes, maternal and infant health, (and) pediatrics" (p. 1578). The authors also specifically state that RDs are essential when working on sport and exercise related health challenges. Not surprisingly then, sports literature has specifically pointed to the need for registered dietitians to be included on interprofessional teams working with athletes (Arvinen-Borrow \& Clement, 2017; Waller et al., 2016). RDs can provide a level of expertise that will assist in optimizing athletic performance as well serving as key member of the holistic care team of athletes. Consequently, a subspecialty of sport dietetics emerged.

\section{Emergence of Sport Dietitians}

The Collegiate and Professional Sports Dietitians Association (CPSDA; n.d.), the leading organization for registered RDs working in sport settings, defines the role of sport dietitians as:

A specialist in sports dietetics and applies evidence-based nutrition knowledge in exercise and sports. RDs specializing in sports dietetics assess, education, and counsel athletes and active individuals. They design, implement, and manage safe and effective nutrition strategies that enhance lifelong health, fitness, and optimal performance. (para. 3) 
RDs can receive a certification in sports nutrition from the Academy of Nutrition and Dietetics: The Board-Certified Specialist in Sports Dietetics (CSSD; Commission on Dietetic Registration, 2019). An individual must meet several criteria to earn the CSSD distinctions: (a) currently registered as an RD, (b) registered as an RD for at least two years; (c) documentation of at least 2,000 hours of practice in a sport setting, and (d) pass the CSSD examination (Commission on Dietetic Registration, 2019). The test must be taken and passed every five years in order to maintain the credential. The CSSD is relatively new as it became an option in 2005 (Academy of Nutrition and Dietetics, 2015). The number of RDs working in college athletic departments has grown not only due to the change in NCAA policy but also the professionalization of the specialty of working in a sport setting. The CPSDA (n.d) estimates that approximately 90 NCAA member institutions had at least one fulltime RD on staff in their athletic department in 2020. The certification adds an additional competence to RDs pursuing this specialty. This is in contrast to other helping professions, such as chaplains and mental health care providers, working in a sport setting. These two professions work in a sport setting but there is no recognized specialization for working in a sport setting. However, mental performance coaches can earn certification through the Association of Applied Sport Psychology (AASP; Wrisberg et al., 2012), and strength and conditioning coaches can earn certification through the National Strength and Conditioning Association (NSCA; Certification Overview, n.d.). The major differentiator among all of these helping professionals is that RDs are licensed to practice in their respective states whereas the other professionals do not require license to practice.

Regardless, there has been limited academic attention to experiences of RDs in the sport context due to the infancy of the specialized profession. Research has mostly focused on the importance of nutrition to performance enhancement (Baker et al., 2014; Holway \& Spriet, 2011; Hull et al., 2016; Hull et al., 2017). Hull and colleagues (2017) found that collegiate baseball teams that had access to a dedicated RD had healthier eating habits and better performance outcomes than teams that did not. Further, some research has identified best practices for RDs working with athletes. Holway and Spriet (2011) suggested that RDs should individualize nutritional plans for each athlete, and Kreider and colleagues (2010) recommend that RDs in sport contexts should stay up-to-date on dietary supplements and other nutritional research to assure athletes are receiving evidence-based advice. However, there appears to be no research that has qualitatively explored the experience of RDs in collegiate athletic departments.

\section{Women in Collegiate Athletics Administration}

Adding another layer to the importance of examining this profession is the role of women working in collegiate athletics administration. The RD profession is dominated by women as more than $93 \%$ of RDs are women (Commission on Dietetic Registration, 2020). Women are underrepresented, marginalized, and face career challenges that men do not in the male-dominated world of sport, and their repre- 
sentation can be a contentious issue (Burton, 2015; Moran-Miller \& Flores, 2011; Walker \& Bopp, 2011). Gender bias in collegiate athletic administration is based on representation in leadership positions, how job responsibilities are assigned, and gendered discourses surrounding positions held by women (Burton et al., 2009; Burton \& Hagan, 2009; Knoppers \& Anthonissen, 2008; Shaw \& Hoeber, 2003; Tiell \& Dixon, 2008).

Collegiate athletics is considered a place that perpetuates masculine hegemony, further legitimizing the power of men in society (Fink, 2008; Whisenant, 2008). Women have struggled to gain entry into collegiate athletics administration (Kamphoff, 2010; Taylor \& Hardin, 2016), and are often put in charge of the "soft" areas of the department such as academic advising, life skills, and women's sports (Grappendorf et al., 2008; Hoffman, 2010). Societal views of masculinity and femininity contribute to the issue in the context of sport, as masculinity is associated with superior leadership and decision-making (Anderson, 2008). Thus, women many times are perceived to lack the skills necessary to assume leadership positions in sport and should have caretaker roles (Burton et al., 2009; Walker \& Satore-Baldwin, 2013). These socially constructed views of masculinity and femininity then lead to gender normalcy and homologous reproduction within sport organizations, which perpetuate the belief that women should hold only specific positions with college athletics (Burton, 2015; Mazerolle et al., 2015; Staurowsky \& DiManno, 2002). Burton (2015) suggested that there are numerous reasons why women have been able to secure only certain positions in sport, including the gendered nature of sport, stereotyping, discrimination, organizational culture, leadership expectations, and occupational turnover. Although the aforementioned may occur within different levels (i.e., society, the organization, and the individual), they work together to limit the opportunities of women within the sport industry (Smith et al., 2019). The experiences of RDs adds to this discussion as food sociologists have identified how food and food preparation offer key insight into how women reproduce and contradict gender norms (Avakian \& Haber, 2005), and cooking is most often associated with being a feminine task (Inness, 2001). Thus, RDs are positioned in an overly feminized role in the overly masculinized culture of college sport.

\section{Method}

RDs are a recognized member of college athletes' interprofessional care time, however, research has yet to understand the experiences of the RDs themselves. Therefore, the purpose of this study is to understand the experiences of female registered dietitians working in college athletics. The study explored the experiences of RDs embedded in athletic departments at the NCAA Division I - FBS level, specifically in the autonomous conferences which are comprised of the Atlantic Coast, Big Ten, Big 12, Pacific 12, and Southeastern conferences. The focus was on this subdivision of Division I, because of the substantial differences in resources within those athletic departments compared to the remaining members of Division I as well as Division II and Division III. Thus, Division I-FBS Autonomous Conference mem- 
bers are more likely to have a RD on staff within the athletic department (National Collegiate Athletic Association, 2020b). Athletic department staff sizes are much larger in this subdivision as well as those departments have all the necessary support personnel, which includes RDs, to provide services to athletes (National Collegiate Athletic Association, 2020a). Thus, it more likely to have find participants who meet the criteria in this study embedded in Division I-FBS Autonomous Conferences member institutions.

\section{Participants}

Purposeful criterion sampling was used to recruit participants for this study as specific characteristics needed to be met prior to participation in the study (Patton, 2002). The criterion for this study were women who were RDs currently employed in Division I FBS - Autonomous Conference athletic departments. Patton (2002) suggests the purposeful sampling yields "information rich" qualitative data because participants are specifically selected within the aims of the study (p. 230). Participants were identified through public, online university staff directories, and contacted via their publicly-available email address. Twenty-nine RDs were contacted with a recruitment email, and nine RDs agreed to be interviewed for this study. Demographic information is reported as a group in an effort to maintain confidentiality due to the small population of participants (Streubert \& Carpenter, 2011; Taylor et al., 2018). All of the participants were women and White. This is representative of the RD profession in general as $93.9 \%$ of RDs are women and $81 \%$ are White. No other ethnicity is represented by more than $4 \%$ of any ethnic group among RDs (Commission on Dietetic Registration, 2020). The average age of participants was 35-years old. Eight participants have their master's degree, and five of the participants have their CSSD certification. The participants have worked in a sports nutrition setting for an average of 7.5 years. Institutional Review Board approval was obtained prior to participant recruitment, and participants signed consent forms prior to their interview.

\section{Data Collection}

Qualitative interviews were utilized for data collection as the focus is on understanding the participants' experiences (Agee, 2009; Denzin \& Lincoln, 2011; Josselon, 2014). Semi-structured interviews were conducted with an interview guide (see Table 1) leading the discussion but the participants led the conversation to facilitate an in-depth discussion of the participants' experience (Merriam \& Tisdell, 2015). The interview guide consisted of 13 open-ended questions and was based on the work of Taylor and Hardin (2016) on their interviews with female collegiate athletics directors and Beasley, Magliocca, Smith, and Hardin (2019) interviews with social workers working in collegiate athletic departments. The open-ended questions gave participants power to express their experiences fully and to allow for follow-up questions, which leads to rich data (Turner, 2010). The questions inquired about the participants' career paths, their interactions with co-workers, the role gender has played in their career as well as their daily responsibilities. All participants were interviewed via the phone, due to geographic considerations (Cachia \& Millward, 2011; Fenig et al., 1993). The average interview length was 29 minutes and ranged from 20 to 60 
minutes. Saturation was determined by the research team to have been met after the ninth interview due to the redundancy of initial themes (Merriam \& Tisdell, 2016). Therefore, no additional recruitment emails were sent. Interviews were recorded, and then transcribed into a Microsoft Word document, which were then copied into Excel for analysis (Saldana, 2015).

\section{Data Analysis}

A thematic analysis was completed following Braun and Clark's (2006) six steps: familiarization with the data, generating initial codes, searching for themes, reviewing themes, defining the themes, and producing the report. The lead researcher began with a close-reading of the transcriptions, from which in-vivo coding, actual words and terms the participants used (Strauss, 1987), were identified as initial codes (Saldana, 2015). A second round of coding was completed to group the in-vivo codes into overarching themes (Braun \& Clarke, 2006). A codebook was then created to define the themes. The lead researcher and another member of the research team independently re-coded each transcript for the themes using this codebook. The research team then met after this individual coding was complete for peer debriefing to discuss any discrepancies in codes and come to a full agreement on all codes to finalize the themes (Saldana, 2015). This adds creditability to the data analysis process by bringing in multiple perspectives (Denzin, 1978; Lincoln \& Guba, 1985).

\section{Trustworthiness}

Several methods were used to ensure the trustworthiness of the qualitative dates. First, member-checking was completed by sending participants a copy of the transcription which they were edited for accuracy (Lindlof \& Taylor, 2011; Lincoln \& Guba, 1985). Only one participant returned the transcript with edits, and all of the edits were incorporated. Second, members of the research team used analytical memos, which are reflexive notes on the connection of certain concepts and the reasons codes were coded in certain ways (Saldana, 2015), which adds credability to researcher process by increasing transparency throughout the research process (Given, 2008).

Grounded in social constructivism and interpretivism, the authors recognize the importance of acknowledging the research team's positionality (Denzin \& Lincoln, 2011). The lead researcher of this study is an RD herself employed in a collegiate athletic department, and conducted the interviews, which inherently brings in biases being a member of the study's population (Peshkin, 1988), and may have influenced interview guide construction, the framing of questions, or data interpretation. Conversely, accompanied with reflexive work (i.e., keeping a researcher's journal), due to shared identity of the lead researcher and participants, she was easily able to build rapport, and was sensitized to professional language during data analysis that may have been missed by people not familiar with the profession (Gobo \& Molle, 2017). Additionally, collaborative work with a research team, such as the use of peer debriefing in the data analysis process, whose members included a doctoral student in sport management and a full professor in sport management both of whose research has focused on holistic care, was used to ensure data trustworthiness (Saldana, 2015). 


\section{Table 1}

\section{Interview Guide}

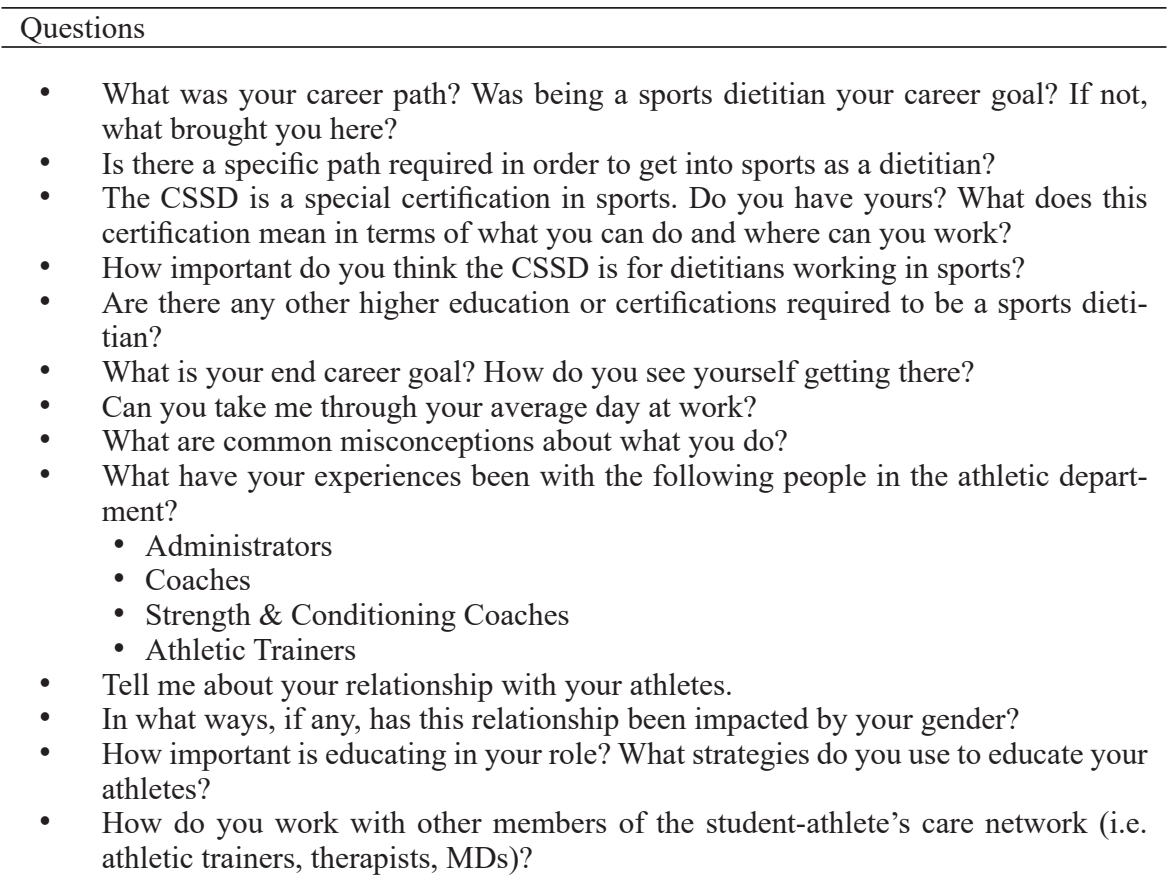

\section{Results}

\section{Professional Transition}

The majority of the participants stated that their initial desire to specialize in sports as a RD stems from their own previous athletic careers or internship experiences in sports nutrition. Participant 8 explained how her experience as a college gymnast made her want to pursue a career in sports. She said:

I did gymnastics and it was about halfway through my junior year and that's really when you're getting deep in to your dietetics courses. (I) was really noticing my own performance. I was performing better, and so I would say about my junior year of undergrad is when I knew that I wanted to work in sports.

Participant 3 mirrored a similar experience, "I was a competitive athlete in high school...so I saw firsthand (how) nutrition played a role in performance and health and body composition."

Although this initial desire for many of the participants to seek a career related to athletics was sparked a at a young age, there were several different paths taken to work in the collegiate setting. However, no matter how, the majority of the participants believed gaining hands-on experience was the most effective pathway to enter 
to the profession. The participants discussed their experience volunteering to not only get their foot in the door, but to understand the day-to-day responsibilities of a dietitian working in a sport setting. Participant 2 explained that it was not until she volunteered that "I saw what they actually did and how involved they were with the teams and the athletes." Participant 6 further acknowledged that, because this is a new field, finding a position as an RD in a collegiate athletic department can be difficult. However, she clarifies this stating, "I think those that are trying to get into the field and are still having trouble getting their foot in the door because they haven't volunteered enough or haven't done the lower level experience to get that first step in the door." Overall, although the participants had different career paths, beginning to volunteer early in one's education experience was identified as the first step in establishing a career as a sport dietitian.

Similarly, all the RDs in the study discussed the importance of completing the dietetic internship. The dietetic internship is an accredited post baccalaureate program that provides the required competencies to take for the Commission on Dietetic Registration Registered Dietitian Exam (2020). All interns must have a minimum of 1,200 hours of supervised practice during this internship. Individuals must have bachelor's degree and complete specific coursework to be qualified for a dietetics internship. As Participant 5 stated, "to get into sports you definitely first need the credential as an RD." The Registered Dietitian credential is not specific to sports, however, as the participants suggest, it is the first step.

RDs who meet minimum requirements have the option to sit for an exam to become a Certified Specialist in Sports Dietetics (CSSD; Commission on Dietetic Registration, 2019). This specialist credential sets registered dietitians who work in sports apart from those who work in a clinical, community, or foodservice setting. Some of the participants did not value this specialized certification, but many still thought the credential, though not required, was a step toward becoming a more qualified professional. Participant 9 explained that having this credential meant:

We're experts. We're professionals. And I think it speaks a lot for our investment. I think that's really important and it shows the commitment and their passion to the field of performance nutrition.

Overall, some type of previous experience with sport-whether as an athlete, through sport-related internships or volunteering - was recommended as a first step in pursuing this career. As Participant 6 summarized, "having some kind of hands-on experience in sports will really help you get your foot in the door."

\section{Nutritional Education}

All of the participants agreed that the most important service they provide to student-athletes is nutritional education. Participant 4 stated that collegiate sports RDs are "educators first and foremost." Participant 2 explained why they feel education is so important to college athletes:

At the end of the day, we're not going to be standing next to the athletes for every meal or many of their meals so for them to be educated enough to make decisions on how to eat. I think is extremely important. They're faced with it multiple times a day. 
Due to the importance of education, many participants stressed this was the main part of their job, and was integrated into all parts of their work. As Participant 8 stressed that as an RD, “you can't give enough education even if you feel like you're repeating yourself. An athlete might hear the same thing four or five times and it might be that fifth time where they actually hear what you're saying."

This education can come in a variety of formats, i.e., teaching a class, individual consults, team talks, cooking demonstrations, nutrition handouts, grocery store tours, or even subliminal messages. Participant 1 described these formats as two different types of education, active education-"like team talks and grocery store tours and cooking classes" - and passive education - "through GroupMe, going to meals, making sure they're eating what they're supposed to be eating, making snack bags." Similarly, Participant 3 explained that they also do active education, such as one-on-one talks with athletes; however, it was in the passive education efforts where true learning happened: "we sort of slide it (nutritional education) in without even realizing that I'm teaching them. So, I think the formal stuff is fine to get in but the equal to that is the informal conversations we end up having that I'm teaching them something." One of the places where a lot of this informal educational conversations where at the nutrition centers and fueling stations. Participant 3 explained this phenomenon by stating:

(The) nutrition centers and fueling stations (have) exposed the dietitian to the students in a much more casual and informal role so they don't have to set up an appointment with you. We do that now but there's just so much more impromptu conversations and education that happens because of the fueling stations.

A key part of this passive education process is creating and developing relationships with college athletes. The participants pointed to the importance of knowing them as individuals first. Participant 1 explained:

I keep (our relationship) professional but also get to know them outside of their sport. Obviously, their sport is super important to them. That's why they're here, but showing them that I care about them as a person and not just as the point guard on our basketball team or the No. 1 pitcher on the softball team.

Participant 9 mirrored this and stated that their relationship with athletes is what drives them the most, joking, "It's all about the person first and again that's what drives me-I don't do it because I enjoy making smoothies that much with a master's degree and 15 years as a dietitian." Overall, education was the main part of the RDs' jobs; however, it appears that it the passive education, happening outside of formalized sessions, is where the most meaningful nutritional learning took place, which could not happen without a trusting relationship with the student-athletes.

\section{(Dis)Respect}

The RD plays an important role on the college athletes' interprofessional care team, and interacts with other athletic staff daily. The role of the RD is still relatively new in sport, so RDs in this study had both positive and negatives experiences with each member on this team. The participants were mixed in responses when asked 
about relationships with administration. Participant 5 explained that their administration is extremely supportive toward nutrition: "our administration is very connected to what we do." However, they continued that this is because the RDs in the department intentionally keep in communication with the upper administration: "I think it's a two-way street. We communicate a lot on what we're doing. We're sending them yearly accomplishments. We do an annual report. We're at senior staff meetings."

Participant 2 echoed this response by stating:

My boss gets nutrition. He understands it. He knows what I do. He's very sharp too so he knows where we should be and what we should be doing. (He knows) where the rest of the sports nutrition programs are headed in the country as well. We communicate pretty regularly and he knows pretty much everything that's going on in nutrition.

Other responses countered this support. For example, Participant 7 stated that the administration views sports nutrition as a cost and not so much an investment: "they understand the need for nutrition and food, but at the end of the day they see the nutrition staff and the food that we are asking for to give to athletes as a cost." Participant 1 took this step further, commenting that their administration does not "fully understand it [sport nutrition]" as "sports nutrition is so new that they probably didn't have a dietitian if they were an athlete." However, similar to the participants with positive experiences with the administration, these participants also spoke about the important of being in communication with senior staff members. As Participant 7 commented, "you're always going to have to push the envelope with administration to say 'we really need to spend more for these athletes on food."' Participant 1 intentionally travels with her teams during the post-season, "because that's really when the administrators are more present and I think it helps as well. They're busy dealing with much bigger fish than what I'm dealing with, so I think it's good for them to actually see what we do." Therefore, a key strategy for the RDs in this study to improve relationships with the athletic administration were keeping in communication with them, and demonstrating the RD's role in the interprofessional team.

All of the participants mentioned their struggles in validating their role and observed an overall lack of knowledge about the profession in both college athletics and in the general public. One of the biggest misconceptions about the profession stemmed from constantly being around food. Participant 1 stated that people often think their job is more "foodservice and that I'm cooking all of the food and serving it" which reinforces the stereotype that RDs are the food police. Participant 6 said “it's not like people are disrespecting us but it's more of they don't realize everything that we are able and capable of doing." Participant 4 added this is not only an issue in sports, but also in the general public. She said "anyone can see something, read something, and suddenly they think they're an expert. I think that's the whole challenge."

Nutrition most likely was the responsibility of either the athletic training staff or strength and conditioning coaches depending on the institution before the emergence of the sport dietitian profession. The relationships with these two groups of professionals has generally been positive. This may be due to the fact that they all 
care for the physical needs of the student-athletes, so they have natural connection with that aspect of care for the student-athletes. Most participants, when discussing strength and conditioning coaches, stated they have a feeling of being "lucky" when describing their relationship. Participant 4 reported, "If you're lucky, you have a strong performance team - strength coaches that support you." Similar to this feeling, Participant 1 stated that they have been "really lucky to have good relationships with the strength coaches and if you have their support it helps so much." The majority of the participants described their relationship with athletic trainers as innately better, with Participant 6 describing this relationship as "our best relationships." All of the participants stated that communication is the key to working together on this interprofessional team in order to build and keep these relationships.

Several participants also pointed out the challenge of overcoming past practices of other members of the staff providing nutritional advice. Participant 4 explained that, before they got to their program, the strength and conditioning staff managed the day-to-day nutrition operations, and they staff members still "chime in on their nutrition opinions" even though "I was hired for a reason." Participant 9 echoed this experiencing indicating its difficult sometimes for other staff members to accept sport dietitians as part of the interprofessional care team.

Interestingly, many of the RDs pointed to their gender as a strength in overcoming professional challenges, provided them credibility and thus a level of respect. Participant 8 explained that "both male and female athletes are more willing to open up about nutrition to a female." Participant 3 mirrored this feeling:

I think I'm looked at a lot as a mom. My relationship with them [athletes] is great and I think a lot of them do look to me like that motherly figure, someone they can go to for anything and it drives me.

Participant 9 explained how other professionals that she has worked with told her "it's good to have a female on our staff, because they're going to talk to you differently and they're going to talk to you about different things than they're going to talk to us about". They continued discussing how being a woman in a male-dominated profession motivated them:

I'm happy, excited that I'm a female in kind of a man's role in that I have the ability to impact my athletes in a different way, in a different light. And kind of bring that piece of diversity to the field in the world of athletics.

Overall, the participants felt both respected, and disrespected, in their position. However, the majority of negative experiences stemmed from others lacking knowledge about sport dietetics as a profession.

\section{Discussion}

The purpose of this study was to explore the experiences of female registered dietitians working in collegiate athletic departments. The study was guided by the interprofessional model of holistic care teams in sport. Holistic care teams have become more popular in both research and practice (Waller et al., 2016). RDs are a key member of athlete care teams, and this study expands the ever-growing literature on 
holistic care for college athletes (Barkley et al., 2018; McHenry, 2020; Waller et al., 2016) by describing the work experiences of registered dietitians in college sports. Overall, the participants offered many insights on the experiences of RDs in a collegiate sport setting, as well as the challenges faced.

Research has examined the challenges women encounter while trying to gain entrance into the collegiate athletics profession (Hardin et al., 2017; Siegele et al., 2020; Taylor et al., 2018). Hardin and colleagues (2017) described the glass door concept as an extension of the glass ceiling. The glass door refers to the difficulties and challenges that women have in entering professions in sport, and thus must develop strategic career plans to find their way into college athletic administration (Smith et al., 2017). The RDs in study employed three specific strategies: earning their master's degree (even though it is not necessary to become registered yet), earning and maintaining their CSSD (specifically for early-career RDs), and gaining experience in sport, many times through unpaid internships. These strategies were specifically used to prove professional competency both as a dietitian and as an athletic expert. This need to "prove" oneself to be respected is common for female professions in sport settings due to the hypermasculine culture of college sport (Taylor \& Hardin, 2016).

It is promising that there is a direct path into becoming a sport dietitian and provides an opportunity for women to enter the collegiate athletics profession. For other emerging professions in sport this is not the case. For example, research with social workers employed in collegiate athletic departments found that many of the social workers accidentally found their way into the profession, not even knowing working in sport-settings was something they could do with their degree (Beasley et al., 2019). Similarly, there is no formalized process for chaplains to become certified to work in sport or even gain access to work in collegiate athletics (Waller et al., 2008). Therefore, even though there are challenges in the career path related to gender, it is a strength of the sport dietetic profession that there are specialized internships in sport-settings and a specialized certification to indicate sport-specific competence.

RDs found strength in their female identity contrary to previous research on gendered experiences in collegiate athletic administration. Gender has been seen as a barrier to positive career experiences for women (Burton et al., 2011; Hoffman, 2010), but the majority of participants in this study actually stated being a woman was a strength in their career as an RD working in college athletics. Women usually take on a more nurturing role that more closely aligns with societal gender norms in sport (Acosta \& Carpenter, 2014; Claussen \& Lehr, 2002; Pent et al., 2007; Raphaely, 2003). Further, the RDs in sport, with their relationship and proximity to food, can take on a motherly role to their athletes. Though conforming to this stereotype, the RD participants felt that their gender, and their natural instincts that are often viewed as weakness, give them strength in their position. The participants' experiences suggested that their gender identity benefited their role as a support staff member. The inclusion of a strengths perspective to research with women is a promising way to empower women in a patriarchal culture, such as sport (Black, 2003; Pollio et al., 1997). 
The women also saw their gender as a strength as they were able to build rapport with their athletes and being a women provided a sense of comfort to the athletes. Research has shown that women are often funneled into the "soft" areas of college sport such as academic counseling or life skills but sport dietetics is certainly not a "soft" area (Hardin et al., 2020). RDs most likely have a degree in nutrition which is a science, and they must be licensed to practice. In fact, the sports dietitian is most likely only one of two licensed professionals working in a college athletic department with the other one being the mental-health care provider. This position allows women to gain entry into the profession and then perhaps continue upward mobility to a senior-level position.

The second major finding from this study was that the RDs' experiences supported the idea of collaborative, interprofessional teams as the most effective way to work in college athletics, just as Arvinen-Barrow and Clement (2015; 2017), in their work with athletic trainers and mental performance coaches, pointed to the importance of athlete access to interprofessional care. Specifically, interprofessional teams - wherein a group of professionals from different specialties work together to form one collaborative care approach — can be more beneficial for collaborative care than a multidisciplinary team-wherein multiple professions work with the same client but provide distinct, rather than collaborative care (Tsakitzidis et al., 2017). Benefits of interprofessional care teams are many times related to the support and communication between professionals to best meet care of clients (Breitbach \& Richardson, 2015; Körner, 2010, McHenry et al., 2020). For example, the participants in this study explained that both informal and formal referrals from support staff have increased, giving athletes more exposure to the RD on a day-to-day basis. Having the support of coaches, athletic trainers, and strength \& conditioning coaches has helped increase athlete awareness of the RDs and the nutrition services provided within interprofessional teams. Therefore, recognizing and including RDs as key member of this interprofessional team, as suggested by the model of athlete care introduced by Waller et al. (2016), is an opportunity for RDs to demonstrate their unique contribution to athlete care, ultimately showing the importance of their services to athletic administrators.

There were, however, misinformed perceptions of registered dietitians by athletic administrators and coaches, which required attention from the RDs. Athletic trainers and strength \& conditioning coaches still gave dietary advice to college athletes, disregarding the skills and knowledge of the RD. Either misunderstanding of what they do on a regular basis, or misunderstanding of what dietetics is, administrators, coaches and support staff require education on the RDs role within the department. This study specifically found that there is some understanding by administrators of the skillset that RDs bring to the support staff, but there are still times when RDs are not recognized for the training, education, and licensing that they have. This may stem from misrepresentation of the profession in popular media. The media misrepresents this profession by photographing RDs with fruit and vegetables in a staged setting rather than in an actual work setting (Porter \& Collins, 2020). Similar to this study, the registered dietitians experienced a misrepresentation as the "food person" 
rather than a licensed professional. Communication and professional education is thus crucial to effectively work together.

This experience is not unique to the emerging profession of sport dietetics. Both sport psychology professionals (Arvinen-Barrow \& Clement, 2017) and social workers (Beasley et al., 2109) in sport have also felt there is a lack of understanding of their role by some members of the interprofessional team. Therefore, as more and more research supports the lack of knowledge of traditional sport professionals (i.e., athletic trainers) about emerging professions in sport (i.e., RDs), there appears to be a need for more systematic interprofessional education for athletic staff. However, true interprofessional work is difficult to learn from the standard model of training that is currently in place, which is constructed around profession-centrism which promotes isolation and elitism (Pecukonis et al., 2008). Health practitioners can learn to "avoid effective communication and diminish the benefits of integrated health care delivery by perpetuating their discipline centric beliefs" (Pecukonis et al., 2008, p. 423). This is seen through the participants' interactions with other support staff members in college athletic departments. Since nutrition guidance formally fell to athletics trainers and strength $\&$ conditioning coaches, these professionals learned their own views of nutrition and can have trouble relinquishing their beliefs when a registered dietitian is present. Interprofessional competence should be taught regularly so that effective athlete-centered care can be achieved. Indeed, scholars suggest that interprofessional education efforts can help overcome barriers, and further cement the role of RDs in interprofessional care teams in other settings (Hark \& Deen, 2017; Johnson, 2013).

Ultimately, even though participants discussed the many ways their gender benefited their work with the athletes, there clearly are gender-related factors at the same time inhibiting the experiences of females RDs in athletic departments; for example, having to employ specific strategies, such as specialized educational certifications, to "prove" their competence to break through the glass door that their male counterparts may not have to consider (Hardin et al., 2017). Furthermore, there are clearly gendered norms related to food preparation (Avakian \& Haber, 2005) that may be contributing the misrepresentation and misunderstanding of the roles of female RDs in the athletic departments. However, much of this misunderstanding is most likely also related to and exacerbated by the fact that sport nutrition is a relatively new profession, and the inclusion of RDs on the interprofessional team, as many of the participants in this study discussed, is relatively new. Therefore, it is additionally necessary to demonstrate as part of the aforementioned interprofessional education the importance that food and nutrition play in the success of athletes. For example, proper nutrition has been found to be necessary for successful injury rehabilitation (Smith-Ryan et al., 2020), and can have impacts on performance outcomes (Logue et al., 2017). Clarifying this importance of nutrition to athletes, coaches, athletics trainers, athletic administrators, and other members of the athletic department may help deconstruct the misrepresentation and misunderstanding of the importance of sport nutrition, and make the case to administrators for more financial and professional support of the RD role in the athletic department. Furthermore, this frames what is commonly thought to be a women's task of food preparation to be an essential part 
of elite athletic success, which may be a step in carving out a space for femininity in a traditionally masculine space.

\section{Limitations and Suggestions for Future Research}

Findings are not meant to be generalized to the RD population as a whole because of the qualitative nature of the data collection. Therefore, future research should explore the experiences of RDs across NCAA divisions, as well as in other sport settings. Furthermore, only female RDs were interviewed due to the overrepresentation of women in the dietetic profession; however, interviews with male RDs working in sport can provide an important perspective. Research should also examine the perceptions of RDs among other members of the interprofessional team, administrators, and athletes to gain a fuller perspective of the role of RDs in athletic departments. Additionally, the participants pointed to their gender as a strength in their practice. As this in contrast to other women in college athletics, future research should examine the experiences of female RDs in sport settings through a feminist lens.

Another line of research that should be examined with RDs is the athlete's perceptions of RDs, and the role RDs play in the overall collegiate experience of the athletes. The interprofessional care team is critical to the athletic success of the athletes as well as their overall holistic development. Examining if the athletes are actually learning healthy dietary habits or just eating what they are told would be an interesting concept to examine. The RDs in this study emphasized that they are focused on educating athletes on healthy eating habits so it would be interesting to explore if the athletes are actually learning what they should or should not be eating or are just doing what they are told by the RDs. This is vital in the overall development of the athletes as this would be beneficial for them when they transition into life post college athletics. Saxe et al. (2017) found that female athletes struggled with their dietary habits when they transitioned out of college athletics. It would then be pertinent to examine if RDs are providing education on healthy eating habits for when athletes are no longer competing at the collegiate level as well as the role RDs play in holistic development of athletes.

\section{Implications}

The insights from the study provide college athletics administrators a glimpse into the profession of RDs working in a collegiate athletic setting. Athletic directors and other senior-level administrators should note the training and expertise these professionals have, and they are not simply the person who makes smoothies after practice. They are most likely one of three athletic support staff required to have a license (professionals providing counseling and medical doctors) so their level of competency is extremely high. Continual education among staff members of the skillset these professionals would be beneficial for everyone in the athletic department to have a better understanding of this profession. Deepening this understanding would increase the efficiency of the interprofessional care team. This directly ties in the theme of (Dis)respect as there seems to be misconceptions of the expertise RDs 
have, and the value they can provide the interprofessional care team. The results of athletic trainers and strength coaches can be seen and measured as athletes recover from injury or gain more muscle mass. It is important to acknowledge that RDs play a critical role in this as well. Providing proper nutrition is critical to injury recover and strength training yet the value of the RD is not always recognized. Athletes are also more likely to value the role of the RDs if administrators are also supportive of $\mathrm{RDs}$ role in the overall care and development of the athletes.

The findings also provide information for RDs who are considering entering into the college athletics. Obtaining an internship in a sport setting is a key for entering the profession. Once in the profession, educating athletes on proper nutrition is vital as well as providing education to administrators so they will have a deeper understanding of the profession. Additionally, nutrition programs should also highlight the career opportunities available in college athletics as they may be a pathway into collegiate athletics administration. Overall, the information from study can help inform future hiring decisions and programmatic decisions by NCAA Division I athletic departments when implementing nutrition services for their athletes and assembling interprofessional care teams.

\section{Conclusion}

It is apparent there is a growing need for sport dietitians in the collegiate athletics. This is particular evident among the NCAA member institutions that are in the Division I - Autonomous conferences. Those members have the necessary financial resources for increasing their staff sizes to ensure complete holistic care for their athletes. These athletes are performing and competing at elite and world-class levels so optimal nutrition is key for their them to reach their peak athletic performance. There have been considerable resources spent to ensure the physical well-being of college athletes in terms of athletic trainers and strength \& conditioning coaches as well as facilities to support these two aspects of student-athlete care. College athletics are now beginning to focus on the complete health of athletes which includes the mental, emotional, and spiritual well-being as well as the physical. Nutrition would fall under the physical aspect of athlete well-being, but would add to the overall holistic care and interprofessional care team. Therefore, understanding RDs' experiences of their professional role in college athletic departments is an important contribution to literature on interprofessional care teams in the athletic context.

\section{References}

2020-21 NCAA Division I Manual (2020). Retrieved from http://www.ncaapublications.com/productdownloads/D121.pdf

Academy of Nutrition and Dietetics. (2015). Board certified specialists in sports dietetics. https://www.scandpg.org/scan/subgroups/sports-performance/be-aboard-certified-sports-dietitian-cssd

Acosta, R. V. \& Carpenter, L. J. (2014). Women in intercollegiate sport: A longitudi- 
nal, national study, thirty-five year update, 1977-2012. Unpublished manuscript. Retrieved from http://acostacarpenter.org/AcostaCarpenter2012.pdf

Agee, J. (2009). Developing qualitative research questions: A reflective process. International Journal of Qualitative Studies in Education, 22(4), 431-447. https:// doi.org/10.1080/09518390902736512

Anderson, E. D. (2008). "I used to think women were weak": Orthodox masculinity, gender-segregation, and sport. Sociological Forum, 23(2), 257-280.

Arvinen-Barrow, M., \& Clement, D. (2015). A preliminary investigation into athletic trainers' views and experiences of multidisciplinary team approach to sports injury rehabilitation. Athletic Training and Sports Health Care, 7(3), 97-107.

Arvinen-Barrow, M. \& Clement, D. (2017). P A preliminary investigation into sport and exercise psychology consultants' views and experiences of multidisciplinary team approach to sports injury rehabilitation. Journal of Interprofessional Care, 31(1), 66-74.

Avakian, V. A., \& Haber, B. (2005). From Betty Crocker and feminist food studies: Critical perspectives on women and food. University of Massachusetts Press.

Baker, L. B., Heaton, L. E., Nuccio, R. P., \& Stein, K. W. (2014). Dietitian-observed macronutrient intakes of young skill and team-sport athletes: Adequacy of pre, during, and postexercise nutrition. Sport Nutrition and Exercise Metabolism, 24, 166-176. http://dx.doi.org/10.1123/ijsnem.2013-0132

Barkley, L., Taliaferro, L.A., Baker, K., \& Garcia, J. (2018). The holistic athletic healthcare model: Addressing the developmental, social, and cultural needs of collegiate athletes. Journal of Higher Education Athletics \& Innovation, 1(3), 26-47. doi: 10.15763/issn.2376-5267.2018.1.3.26-47

Beasley, L., Magliocca, J., Smith, Z., \& Hardin, R. (2019). The Role of Social Workers in NCAA Division I Athletic Departments. North American Society for Sport Management. New Orleans, La.

Berg, B. K., \& Warner, S. (2019). Advancing college athlete development via social support. Journal of Issues in Intercollegiate Athletics, 12, 87-113.

Black, C. J. (2003). Translating principles into practice: Implementing the feminist and strengths perspectives in work with battered women. AFFILIA, 18(3), 332349. https://doi.org/10.1177/0886109903254578

Braun, V., \& Clark, V. (2006). Using thematic analysis in psychology. Qualitative Research in Psychology, 3(2), 77-101.

Breitbach, A. P., \& Richardson, R. (2015). Interprofessional education and practice in athletic training. Athletic Training Education Journal, 10(2), 170-182. doi: $10.4085 / 1002170$

Burns, R. D., Schiller, M. R., Fada, R. D., Merrick, M. A., \& Wolf, K. N. (2004). Intercollegiate student-athlete use of nutritional supplements and the role of athletic trainers and dietitians in nutrition counseling. Journal of the American Dietetic Association, 104, 246-249. doi: 10.1016/j.jada.2003.11.013

Burton, L. (2015). Underrepresentation of women in sport leadership: A review of research. Sport Management Review, 18(2), 155-165. http://dx.doi.org/10.1016/j. smr.2014.02.004 
Burton, L., Barr, C. A., Eink, J. S., \& Bruening, J. E. (2009). “Think athletic director, think masculine?": Examination of the gender typing of managerial suhroles within athletic administration positions. Sex Roles, 61, 416-426.

Burton, L. J., Grappenforf, H., \& Henderson, A. (2011). Perceptions of gender in athletic administration: Utilizing role congruity to examine (potential) prejudice against women. Journal of Sport Management, 25, 36-45.

Burton, L. J., \& Hagan, E. M. (2009). Examination of job description in intercollegiate athletics administration: Application of gender typing of managerial subroles. The Sport Management and Related Topics Journal, 5, 84-95.

Cachia, M., \& Millward, L. (2011). The telephone medium and semi-structured interviews: A complementary fit. Qualitative Research in Management and Organizations, 6(3), 265-277.

Casas-Agustench, P., Megias-Rangil, I., \& Babio, N. (2020). Economic benefit of dietetic-nutritional treatment in multidisciplinary primary care team. Nutricion Hospitalaria, 37(4), 643-886. https://europepmc.org/article/med/32686448

Certification Overview (n.d.). Retrieved from https://www.nsca.com/certification-overview/

Claussen, C.L., \& Lehr, C. (2002). Decision making authority of senior woman administrators. International Journal of Sport Management, 3(3), 215-228.

Collegiate and Professional Sports Dietitians Association. (n.d.). About CPSDA. https://www.sportsrd.org/

Collegiate and Professional Sport Dietitians Association (2012). Position statement: Recommend feeding protocol for all athletes. Retrieved from https:// www.sportsrd.org/wp-content/uploads/2018/10/CPSDA-Position-Statement Oct_25_2012.pdf

Commission on Dietetic Registration (2019). CSSD eligibility requirements. https:// www.cdrnet.org/cssd-eligibility-requirements-update

Commission on Dietetic Registration (2020). Registered dietitian (RD) and registered dietitian nutritionist (RDN) by demographics. Retrieved from https:// www.cdrnet.org/registry-statistics-new?id=1779\&actionxm=ByDemographics

Dejesse, L. D., \& Zelman, D. C. (2013). Promoting optimal collaboration between mental health providers and nutritionist in the treatment of eating disorders. Eating Disorders, 21(3), 185-205. https://doi.org/10.1080/10640266.2013.779173

Denzin, N. K. (1978). Sociological Methods. McGraw-Hill.

Denzin, N. K., \& Lincoln, Y. S. (2011). Introduction: The discipline and practice of qualitative Research (pp. 1-20). In N. K. Denzin \& Y.S. Lincoln. The SAGE handbook of qualitative research (4th ed.). Sage.

Eliot, K. A., \& Kolasa, K. M. (2015). The value in interprofessional, collaborative-ready nutrition and dietetics practitioners. Journal of the Academy of Nutrition and Dietetics, 115(10), 1578-1588. https://doi.org/10.1016/j. jand.2015.03.025

Fenig, S., Levav, L., Kohn, R. and Yelin, N. (1993). Telephone vs face-to-face interviewing in a community psychiatric survey. American Journal of Public Health, 
83(6), 896-8.

Fink, J. (2008). Gender and sex diversity in sport organizations: Concluding comments. Sex Roles, 58(1-2), 146-147.

Given, L. M. (2008). Memos and memoing. In L. M. Given (Ed.), The SAGE encyclopedia of qualitative research methods (pp. 506-509). Sage.

Gobo, G., \& Molle, A. (2017). Doing Ethnography. Sage.

Gurau, J., Cronk, A., Pelliccia, M., \& Vandenbussche, K. (2013). Role of the nutrition professional in high-risk obstetrics inpatient teams. Canadian Journal of Dietetics Practice and Research, 74(2), 75-79. doi: 10.3148/74.2.2013.75

Grappendorf, H., Pent, A., Burton, L., \& Henderson, A. (2008). Gender role stereotyping: A qualitative analysis of senior woman administrators' perceptions regarding financial decision-making. Journal of Issues in Intercollegiate Athletics, 1, 26-45.

Hardin, R., \& Pate, J. (2013). Playbook vs. textbook: Academic transitioning of NCAA FBS Division I football student-athletes. Journal for the Study of Sports and Athletes in Education, 7(3), 229-244.

Hardin, R., Taylor, E., Siegele, J., \& Smith, A. (2017). The glass door: Early-career women in collegiate athletics. In A. Milner \& J. Braddock (Eds.), Women in sports: Breaking barriers, facing obstacles, Volume 2 (pp. 243-263). Praeger.

Hardin, R., Veraldo, C. M., Taylor, E. A., \& Jilka, D. (2020). The relationship between job satisfaction and burnout: Athletic academic counselors. Journal of Student-Athlete Educational Development and Success, 2, 103-137.

Hardin, R., Waller, S. N., \& Dzikus, L. (2019). NCAA athletic directors' perceptions of sports chaplains: An exploratory study of the value of collegiate sports chaplains in the United States. Journal of Contemporary Athletics, 13(4), 281-296.

Hark, L. A., \& Deen, D. (2017). Position of the Academy of Nutrition and Dietetics: Interprofessional education in nutrion as an essential component of medical education. Journal of the Academy of Nutrition and Dietetics, 117(7), 1104-1113. https://doi.org/10.1016/j.jand.2017.04.019

Hoffman, J. (2010). The dilemma of the senior woman administrator role in intercollegiate athletics. Journal of Issues in Intercollegiate Athletics, 3, 53-75.

Holway, F. E., \& Spriet, L. L. (2011). Sport-specific nutrition: Practical strategies for team sports. Journal of Sports Sciences, 29(sup 1), 112-125. https://doi.org/10. 1080/02640414.2011.605459

Hosick, M. B. (2014). Council approves meals, other student-athlete well-being rules. Retrieved from http://www.ncaa.org/about/resources/media-center/news/ council-approves-meals-other-student-athlete-well-being-rules

Huffman, L., Waller, S., \& Hardin, R. (2016). The sport chaplain's role in the holistic care model for collegiate athletes in the United States. Practical Theology, 9(3), 226-241.

Hull, M. V., Jagim, A. R., Oliver, J. M., Greenwood, M., Busteed, D. R., \& Jones, M. T. (2016). Gender differences and access to a sports dietitian influence dietary habits of collegiate athletes. Journal of the International Society of Sports $\mathrm{Nu}$ trition, 13(38), 1-16. 
Hull, M. V., Neddo, J., Jagim, A. R., Oliver, J. M., Greenwood, M., \& Jones, M. T. (2017). Availability of a sports dietitian may lead to improved performance and recovery of NCAA division I baseball athletes. Journal of International Society of Sports Nutrition, 14(29), 1-8.

Innes, S. A. (2001). American women and culinary culture. University of Iowa Press. Jessop, A. (2014). The NCAA approves unlimited meals for Division I athletes after Shabazz Napier complains of going hungry: The lesson for other college athletes. Retrieved from https://www.forbes.com/sites/aliciajessop/2014/04/15/ the-ncaa-approves-unlimited-meals-for-division-i-athletes-after-shabazznapier-complains-of-going-hungry-the-lesson-for-other-college-athletes/?s$\mathrm{h}=43 \mathrm{~b} 754 \mathrm{a} 915 \mathrm{bd}$

Johnson, J. (2013). Embracing collaborative health care training for optimal patient care. Journal of the Academy of Nutrition and Dietetics, 113(9), A65. doi: 10.1016/j.jand.2013.06.229

Jortberg, B. T., \& Flemming, M. O. (2014). Registered dietitian nutritionists bring value to emerging health care delivery models. Journal of the Academy of Nutrition and Dietetics, 114(12), 2017-2022. https://doi.org/10.1016/j.jand.2014.08.025

Josselon, R. (2014). Introduction to qualitative psychology. Qualitative Psychology, 1(1), 1-3. doi: 10.1037/

Kamphoff, C. (2010). Bargaining with patriarchy: Former women coaches' experiences and their decision to leave collegiate coaching. Research Quarterly for Exercise and Sport, 81, 367-379. http://dx.doi.org/10.1080/02701367.2010.10 599684

Knoppers, A., \& Anthonissen, A. (2008). Gendered managerial discourses in sport organizations: Multiplicity and complexity. Sex Roles, 58, 93-103.

Körner, M. (2010). Interprofessional teamwork in medical rehabilitation: A comparison of multidisciplinary and interdisciplinary team approach. Clinical Rehabilitation, 24, 745-755. doi: 10.1177/0269215510367538

Kreider, R. B., Wilborn, C. D., Taylor, L., Campbell, B., Almada, L., Collins, R..., \& Antonio, J. (2010). ISSN exercise \& sport nutrition review: Research \& recommendations. Journal of the International Society of Sports Nutrition, 7(7), 1-43.

Leung, L. B., Yoon, J., Rubenstein, L. V., Post, E. P., Metzger, M. E., Wells, K, B..., Escare, J. J. (2018). Journal of the American Board of Family Medicine, 31(1), 38-48. doi: 10.3122/jabfm.2018.01.170157

Lincoln, Y. S., \& Guba, E.G. (1985). Naturalistic Inquiry. Sage Publications.

Lindlof, T. R., \& Taylor, B. C. (2011). Qualitative Communication Research Methods. Sage Publications.

Logue, D., Madigan, S. M., Delahunt, E., Heinen, M., McDonnell, S. J., \& Corish, C. A. (2017). Low energy availability in athletes: A review of prevalence, dietary patterns, physiological health, and sports performance. Sports Medicine, 48, 7396. doi: 10.1007/s40279-017-0790-3

Mailliet, J. O., Schwartz, D. B., \& Posthauer, M. E. (2013). Position of the Academy of Nurtition and Dietetics: Ethical and legal issues in feeding and hydration. Journal of the Academy of Nutrition and Dietetics, 113(6), 828-833. https://doi. 
org/10.1016/j.jand.2013.03.020

Mazerolle, S. M., Burton, L., \& Cotrufo, R. J. (2015). The experiences of female athletic trainers in the role of the head athletic trainer. Journal of Athletic Training, 50(1), 71-81.

McHenry, L. K., Beasley, L., Zakrajsek, R. A., \& Hardin, R. (October 2020). A Call for Collaboration in the Provision of Holistic Athlete Care. Association for Applied Sport Psychology. Orlando, Fla.

Merriam, S. B., \& Tisdell, E. J. (2015). Qualitative research: A guide to design and implementation (4th edition). Hoboken, NJ: Wiley Publishing Company.

Moran-Miller, K. E., \& Flores, L. Y. (2011). Where are the women in women's sports? Predictors of female athletes' interest in a coaching career. Research Quarterly for Exercise and Sport, 82(1), 109-117.

National Collegiate Athletic Association (2020a). NCAA Demographics Database [Data visualization dashboard]. Retrieved from http://www.ncaa.org/about/resources/research/ncaa-demographics-database

National Collegiate Athletic Association (2020b). NCAA Financial Database [Data visualization dashboard]. Retrieved from http://www.ncaa.org/about/resources/ research/finances-intercollegiate-athletics-database

NCAA Academic Affairs and Membership Staff (2013). 2013-14 NCAA Division I Manual. Indianapolis, IN: National Collegiate Athletic Association.

Newman, T. J., Okamoto, K., Kimiecik, C., Sohns, E., Burns, M., \& Magier, E. (2019). The role of social workers in sport: shared values, interprofessional collaborations, and unique contributions. Journal of Sport Psychology in Action, 10(3), 160-173. https://doi.org/10.1080/21520704.2019.1642270

Pate, J., Stokowski, S., \& Hardin, R. (2011). Third time's a charm: The case of Tennessee's four junior football players who endured three different head coaches in three seasons. Journal of Issues in Intercollegiate Athletics, 4, 354-369.

Patton, M. C. (2002). Two decades of development in qualitative inquiry: A personal, experimental perspective. Qualitative Social Work, 1(3), 261-283.

Pecukonis, E., Doyle, O., \& Bliss, D. L. (2008). Reducing barriers to interprofessional training: Promoting interprofessional cultural competence. Journal of Interprofessional Care, 22(4), 417-428. doi: 10.1080/13561820802190442

Pent, A., Grappendorf, H., \& Henderson, A. (2007). Do they want more? An analysis of NCAA senior woman administrators' participation in financial decision making. Journal for the Study if Sports and Athletes in Education, 1(2), 175-194. doi: $10.1179 /$ ssa.2007.1.2.157

Peshkin, A. (1988). In search of subjectivity: One's own. Educational Researcher, 17, 17-21. https://doi.org/10.3102/0013189X017007017

Phillips, S. (2014). Shabazz Napier: 'there are hungry nights that I go to bed and I'm starving.' Retrieved from https://collegebasketball.nbcsports.com/2014/04/07/ shabazz-napier-there-are-hungry-nights-that-i-go-to-bed-and-im-starving/

Pollio, D. E., McDonald, S. M., \& North, C. S. (1997). Combining a strengths-based approach and feminist theory in group work with persons 'on the streets'. Social Work with Groups, 3-4(19), 5-20. 
Porter, J., \& Collins, J. (2020). Do images of dietitians on the Internet reflect the profession? Journal of Human Nutrition and Dietetics, ahead of print. doi: 10.1111/ jhn. 12793

Raney, L. E. (2015). Integrating primary care and behavioral health: The role of the psychiatrist in the collaborative care model. The American Journal of Psychiatry, 172(8), 721-728. doi: 10.1176/appi.ajp.2015.15010017

Raphaely, D. (2003). An analysis of the senior woman administrator position within NCAA athletics departments. Unpublished Master's Thesis. University of San Francisco.

Saldana, J. (2015). The coding manual for qualitative researchers. Sage.

Samuelson, M., Tedeschi, P., Aarendonk, D., De La Cuesta, C., \& Groenewegen, P. (2012). Improving interprofessional collaboration in primary care: Position paper of the European Forum for Primary Care. Quality in Primary Care, 20, 303-312. Retrieved from https://pubmed.ncbi.nlm.nih.gov/23113915/

Saxe, K., Hardin, R., Taylor, E. A., \& Pate, J. R., (2017). Transition blues: The experience of female collegiate student-athletes. Journal of Higher Education Athletics and Innovation, 1(2), 25-48.

Schimmel, C., Etzel, E., Wrisberg, C. Watson II, J. C., Connole, I. J., \& Shannon, V. (2014). NCAA athletic administrators' preferred characteristics of sport psychology consultants: A consumer market analysis. Sport Psychologist, 28(4), 406-417.

Shaw, S., \& Hoeber, L. (2003). "A Strong Man Is Direct and a Direct Woman Is a Bitch": Gendered Discourses and Their Influence on Employment Roles in Sport Organizations. Journal of Sport Management. 17, 347-375.

Siegele, J., Hardin, R., Smith, A. B., \& Taylor, E. A. (2020). "She is the Best Female Coach": NCAA Division I Female Swimming Coaches' Experiences of Sexism. Journal of Intercollegiate Sport, 13(1), 93-118.

Siopis, G., Colagiuri, S., \& Allman-Farinelli, M. (2020). Dietitians' experiences and perspectives regarding access to and delivery of dietetic services for people with type 2 diabetes mellitus. Heliyon, 6(2), e03344. doi: 10.1016/j.heliyon.2020. $\mathrm{e} 03344$

Smith, A. B., Taylor, E. A., \& Hardin, R. (2017). Career entry and experiences of female graduate assistants in collegiate athletics. Journal of Issues in Intercollegiate Athletics, 10, 234-260.

Smith, A. B., Taylor, E. A., Siegele, J.., \& Hardin, R. (2019). NCAA Division I senior woman administrators' perceptions on barriers to career mobility. Journal of Issues in Intercollegiate Athletics 12, 479-504.

Smith-Ryan, A. E., Hirsch, K. R., Saylor, H. E., Gould, L. M., \& Blue, M. N. M. (2020). National considerations and strategies to facilitate injury recovery and rehabilitation. Journal of Athletic Training, 55(9), 918-930. doi: 10.4085/10626050-550-19

Smuts, J. C. (1926). Holism and evolution. Macmillan.

Staurowsky, E. J., \& DiManno, J. (2002). Young women talking sports and careers: A glimpse at the next generation of women in sport media. Women in Sport \& 
Physical Activity Journal, 11(1), 127-161.

Strauss, A. L. (1987). Qualitative analysis for social scientists. Cambridge University Press.

Streubert, H. J., \& Carpenter, D. R. (2011) Qualitative Research in Nursing: Advancing the Humanistic Imperative. Wolters Kluwer.

Taylor, E. A., \& Hardin, R. (2016). Female NCAA Division I athletic directors: Experiences and challenges. Women in Sport in Physical Activity, 24, 14-25. doi: doi/10.1123/wspaj.2014-0038

Taylor, E. A., Siegele, J. L., Smith, A. B., \& Hardin, R. (2018). Applying career construction theory to female NCAA Division I conference commissioners. Journal of Sport Management, 32(4), 321-333.

Thomas, D. (2000). The dietitian's role in the treatment of eating disorders. Nutrition Bulletin, 25, 55-60. doi: 10.1046/j.1467-3010.2000.00012.x

Tiell, B., \& Dixon, M. (2008). Roles and tasks of the Senior Woman Administrator (SWA) in intercollegiate athletics: A role congruity perspective. Journal for the Study of Sports and Athletes in Education, 2(3), 339-361.

Tjale, A. A., \& Bruce J. (2007). A concept analysis of holistic nursing care in pediatric nursing. Curationis, 30(4), 45-52.

Tsakitzidis, G., Antheirens, S., Timmermans, O., Truijen, S., Meulemans, H., \& Van Royen, P. (2017). Do not confuse multidisciplinary task management in nursing home with interprofessional care! Primary Health Care Research \& Development, 18, 591-602. doi: 10.1017/S146342361700024X

Turner, D. W. (2010). Qualitative interview design: A practical guide for novice investigators. The Qualitative Report, 15(3), 754-760. Retrieved from https://nsuworks.nova.edu/tqr/vol15/iss3/19

Walker, N. A., \& Bopp, T. (2010). The underrepresentation of women in the male-dominated sport workplace: Perspectives of female coaches. Journal of Workplace Rights, 15(1). http://dx.doi.org/10.2190/WR.15.1.d

Walker, N., \& Sartore-Baldwin, M. (2013). Hegemonic masculinity and the institutionalized bias toward women in men's collegiate basketball: What do men think?. Journal of Sport Management, 27, 303-315.

Waller, S., Dzikus, L. \& Hardin, R. (2008). Collegiate sport chaplaincy: problems and promise. Journal of Issues in Intercollegiate Athletics, 1, 107-123.

Waller, S. N., Huffman, L. T., \& Hardin, R. L. (2016). The sport chaplains' role in the holistic care model for collegiate athletes in the United States. Practical Theology, 9, 226-241. doi: 10.1080/1756073X.2016.1221642

Warner, M. F., Miklos, K. E., Strowman, S. R., Ireland, K., \& Pojednic, R. M. (2018). Improved access to and impact of registered dietitian nutritionist services associated with an integrated care model in high-risk, minority population. Journal of the Academy of Nutrition and Dietetics, 118(10), 1951-1957. https://doi. org/10.1016/j.jand.2018.05.004

Whisenant, W. A. (2008). Sustaining male dominance in interscholastic athletics: A case of homologous reproduction... or Not?. Sex Roles. 58, 768-775.

Wood, E. A., Dittmore, S. W., Stokowski, S., Li., B. (2018). Division I athletic di- 
rector trends and perceptions of requisite professional skills. Journal of Higher Education Athletics and Innovation 1(5), 102-122.

Wrisberg, C., Withycombe, J. L., Simpson, D., Loeberg, L.A., \& Reed. A. (2012). NCAA Division I administrators' perceptions of the benefits of sport psychology services and possible roles for a consultant. Sport Psychologist, 26(1), 16-28.

Zakrajsek, R. A., Martin, S. B., \& Wrisberg, C. (2016). National Collegiate Athletic Association Division I certified athletic trainers' perceptions of the benefits of sport psychology services. Journal of Athletic Training, 51(5)., 398-405.

Zamanzadeh, V., Jasemi, M., Valizadeh, L., Keogh, B., \& Takeghani, F. (2015). Effective factors in providing holistic care: A qualitative study. Journal of Palliative Care, 21(2), 214-227. doi: 10.4103/0973-1075.156506 